\title{
Pathology gone to pot: Paleopathology on Mochica ceramics
}

\author{
Arthur Gryfe MD FRCPC \\ Director of Laboratory Medicine, Queensway General Hospital, Etobicoke, Ontario
}

$P$ aleopathology is the study of disease in ancient cultures. Information in this area is usually acquired by examining human remains. Usually, these consist of dry bones, which provide little or no information of interest to the plastic surgeon. Even when soft tissues have been preserved by artificial or natural mummification, surface features are frequently distorted or obliterated by the elements or other natural phenomena. However man-made artifacts may provide fascinating depictions of various disease states.

Ancient South American ceramics sometimes portray physical abnormalities which fall into the realm of plastic surgery; however, interpreting these abnormalities often involves speculation, not only in diagnosing the lesion but also in judging whether the depiction is pathological at all. This article will show some pots and figures created by ancient Mochica craftsmen of Peru, some of which portray obvious lesions and others in which the presence of disease is merely speculative.

The Mochicas occupied the Moche Valley in coastal northern Peru from approximately $300 \mathrm{BC}$ to about $700 \mathrm{AD}$. They were a bellicose people who built huge architectural structures and sculpted lifelike ceramics. The latter include people and animals engaged in everyday activities. Their pots show human faces laughing and crying, figures kneeling and sitting, and couples in explicit sexual poses.

The Museum of Anthropology and Archaeology in Lima, Peru possesses a superb collection of Mochica pottery. On one ceramic vessel there is a fine depiction of harelip (Figure 1). This is a rare finding in paleopathological material: few mummies have been described with harelip or cleft palate, and although there are ceramics, especially from Mexico, which show harelip, these were made by more recent cultures. We are unaware of any pot earlier than this Mochica one showing this deformity. The appearance of this abnormality in art does not necessarily reflect an increase in incidence, but may be indicative of a higher culture which enabled the afflicted to survive. Most of those affected perished in infancy, either due to malnutrition (since they could

Correspondence and reprints: Dr Arthur Gryfe, Queensway General Hospital, 150 Sherway Drive, Etobicoke, Ontario M9C IA5 not suckle effectively) or infanticide. The fact that Figure 1 features a rare depiction of harelip in an adult, therefore, makes it particularly interesting.

Other pots in the Lima museum are almost as easy to decipher. One shows a person suffering excruciating pain (Figure 2), while a ceramic figurine of a man with a tattooed face probably depicts bilateral arm amputations (Figure 3). Another vessel exhibits crescentic lesions of undetermined

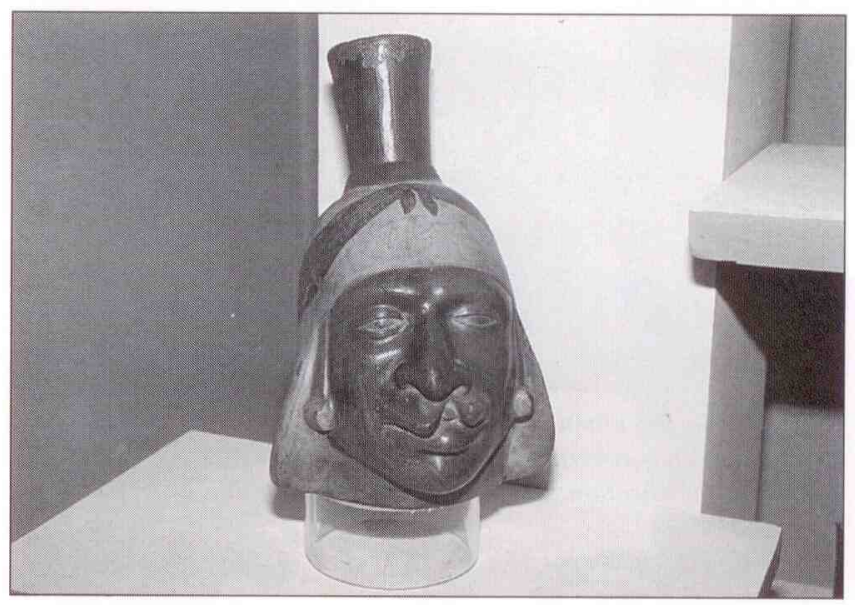

Figure 1) Moche ceramic vessel depicting harelip, and possible asymmetry of eyes. Museum of Anthropology and Archaeology, Lima, Peru

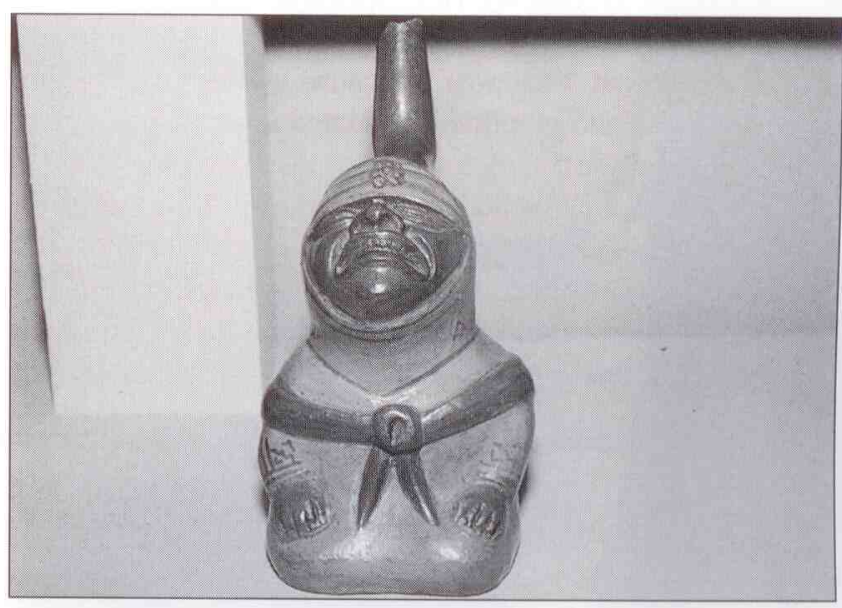

Figure 2) Moche ceramic vessel of kneeling figure in pain. Museum of Anthropology and Archaeology, Lima, Peru 


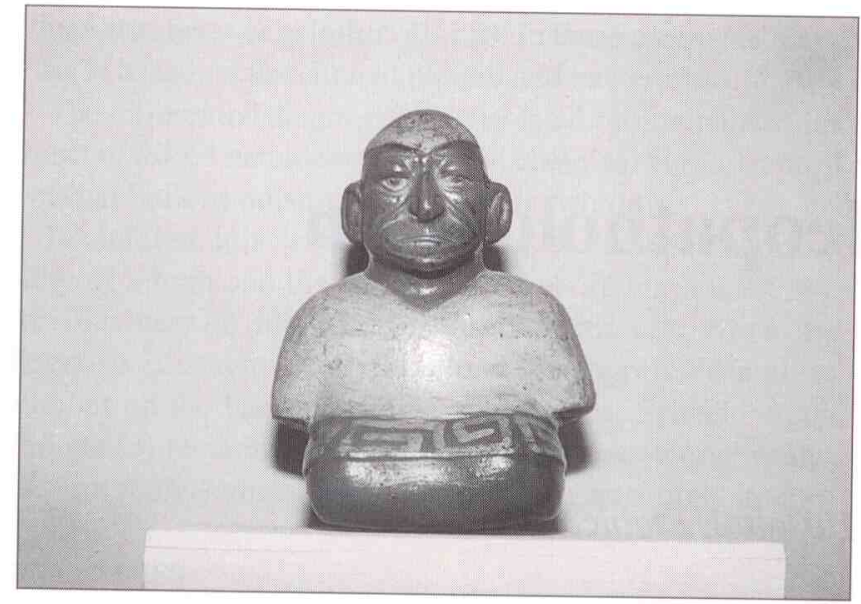

Figure 3) Moche ceramic vessel of man with bilateral arm amputations and facial tattoos. Museum of Anthropology and Archaeology, Lima, Peru

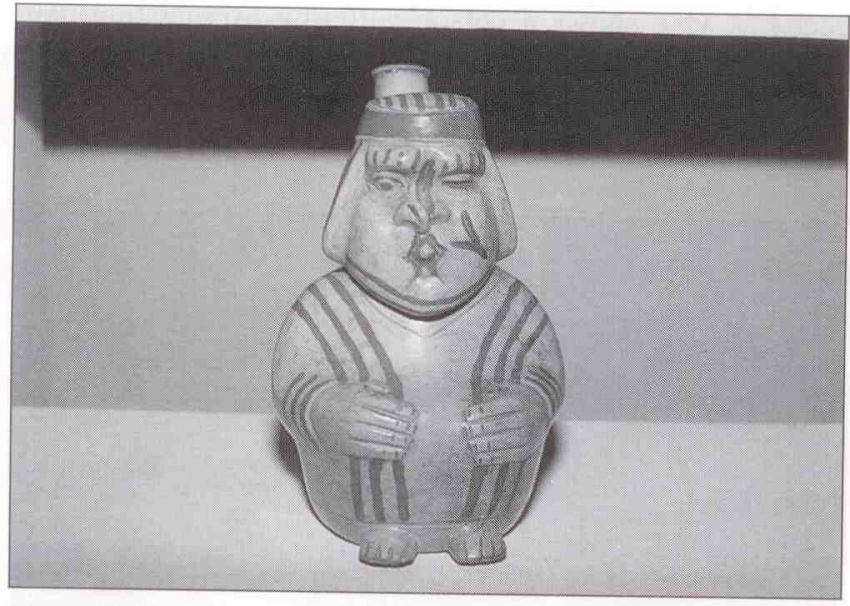

Figure 4) Moche ceramic vessel showing kneeling figure with uniform, crescentic lesions covering face, head, body and limbs, consistent with deliberate scarification. Museum of Anthropology and Archaeology, Lima, Peru

etiology covering the head, body and limbs of a seated or kneeling figure (Figure 4). Here speculation comes into action. Do these lesions represent a skin rash or deliberate scarification? And what was the cause of the severely distorted eye, nose and mouth of the seated individual depicted on the pot in Figure 5?

The George R Gardiner Museum of Ceramic Art in Toronto has a small but interesting pre-Columbian South and Central American collection. A Mochica stirrup spout vessel (G83.1.160) shows a seated man with a lump in his left cheek (Figure 6). Is this a lesion which could be cured by the

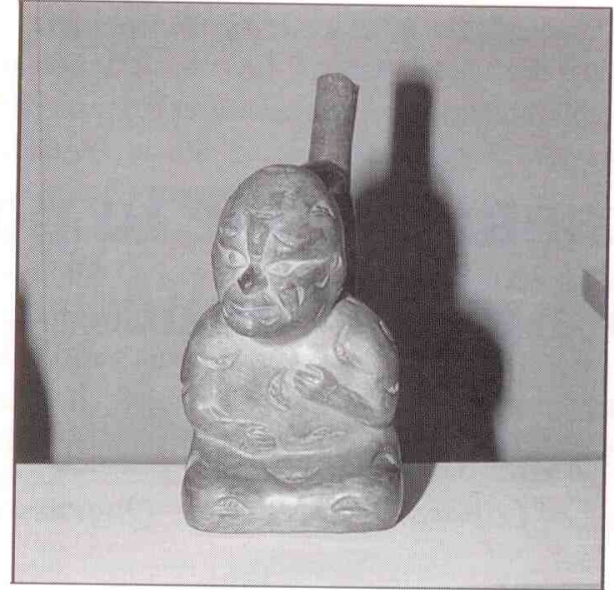

Figure 5) Moche ceramic vessel of seated figure with blind left eye, and scarred nose, mouth and left cheek. Museum of Anthropology and Archaeology, Lima, Peru

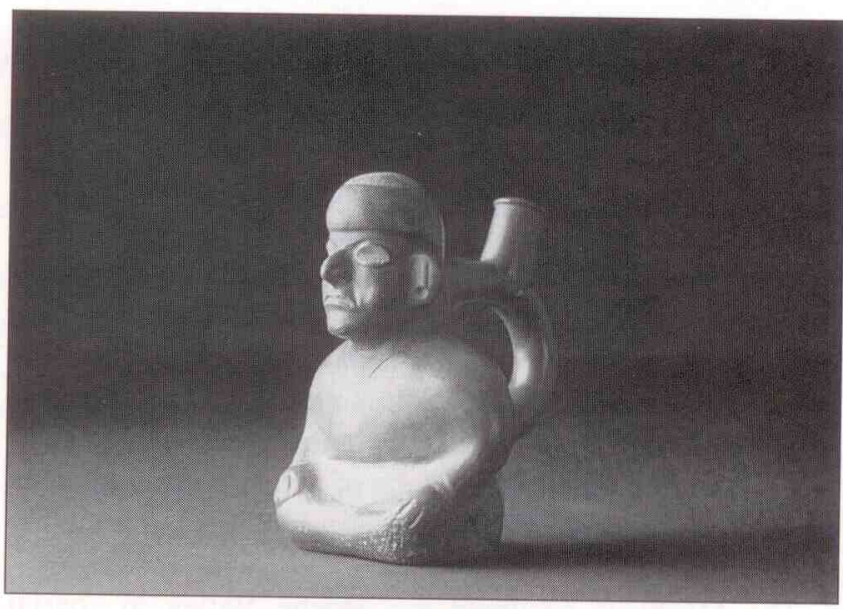

Figure 6) Moche stirrup spout vessel showing seated man with lump in his left cheek. Is he chewing coca leaves or does he have a tumour amenable to surgery? Note also the earlobe holes for ornamental plugs. Photograph courtesy of the George R Gardiner Museum of Ceramic Art, Toronto (G83.1.160)

surgeon's scalpel? It is possible, but so is another explanation - it was and still is the custom in Peru and other South American countries to chew coca. Plastic bags stuffed with leaves can be purchased cheaply in most street markets today. It may be that the seated man is merely chewing his daily ration of coca leaves. This ceramic figure also bears large holes in his earlobes for wearing ornamental plugs.

Several museums have collections of Mochica and other pottery showing lesions curable by plastic or general surgery. Some are labelled with the correct diagnosis and some are not, but then again, some may not be lesions at all. 